\title{
Initial study of sediment antagonism and characteristics of silver nanoparticle-coated biliary stents in an experimental animal model
}

This article was published in the following Dove Press journal:

International Journal of Nanomedicine

28 April 2016

Number of times this article has been viewed

\author{
Yigeng Tian ${ }^{1, *}$ \\ Mingfeng $\mathrm{Xia}^{2}, *$ \\ Shuai Zhang ${ }^{3}$ \\ Zhen $\mathrm{Fu}^{4}$ \\ Qingbin Wen ${ }^{2}$ \\ Feng $\mathrm{Liu}^{4}$ \\ Zongzhen $\mathrm{Xu}^{4}$ \\ Tao $\mathrm{Li}^{4}$ \\ $\mathrm{Hu} \operatorname{Tian}^{4}$ \\ 'Department of Physics, School of \\ Physics and Technology, University \\ of Jinan, Jinan, Shandong, People's \\ Republic of China; ${ }^{2}$ Department \\ of Surgery, Shandong University of \\ Traditional Chinese Medicine, Jinan, \\ Shandong, People's Republic of China; \\ ${ }^{3}$ Department of General Surgery, \\ Sixth People's Hospital of Jinan, Jinan, \\ Shandong, People's Republic of China; \\ ${ }^{4}$ Department of General Surgery, \\ Shandong Provincial Qianfoshan \\ Hospital, Shandong University, Jinan, \\ Shandong, People's Republic of China \\ *These authors contributed equally \\ to this work
}

Correspondence: Hu Tian

Department of General Surgery,

Shandong Provincial Qianfoshan Hospital,

Shandong University, No 16766, Jingshi

Road, Jinan, Shandong 2500I4, People's

Republic of China

$\mathrm{Tel}+8653$ I 89268684

Fax +86 53I 82963647

Email tianhu6585@।63.com
Objective: Plastic biliary stents used to relieve obstructive jaundice are frequently blocked by sediment, resulting in loss of drainage. We prepared stents coated with silver nanoparticles (AgNPs) and compared their ability to resist sedimentation with Teflon stents in a beagle model of obstructive jaundice.

Methods: AgNP-coated Teflon biliary stents were prepared by chemical oxidation-reduction and evaluated in an obstructive jaundice model that was produced by ligation of common bile duct (CBD); animals were randomized to two equal groups for placement of AgNP-coated or Teflon control stents. Liver function and inflammatory index were found to be similar in the two groups, and the obstruction was relieved. Stents were removed 21 days after insertion and observed by scanning and transmission electron microscopy. The AgNP coating was analyzed by energy dispersive X-ray analysis (EDXA), and the composition of sediment was assayed by Fourier-transform infrared (FTIR) spectroscopy.

Results: Electron microscopy revealed a black, closely adherent AgNP stent coating, with thicknesses of 1.5-6 $\mu \mathrm{m}$. Sediment thickness and density were greater on Teflon than on AgNP-coated stents. EDXA confirmed the stability and integrity of the AgNP coating before and after in vivo animal experimentation. FTIR spectroscopy identified stent sediment components including bilirubin, cholesterol, bile acid, protein, calcium, and other substances.

Conclusion: AgNP-coated biliary stents resisted sediment accumulation in this canine model of obstructive jaundice caused by ligation of the CBD.

Keywords: silver nanoparticles, biliary stent, stent sediment, characterization, animal model

\section{Introduction}

Nanomaterials are increasingly widely used in the biomedical field, ${ }^{1-5}$ and silver nanoparticles (AgNPs) have good biocompatibility with biological tissue. ${ }^{6}$ In the clinic, there are many patients with obstructive jaundice caused by benign or malignant disease. In addition to surgery, endoscopic retrograde cholangiopancreatography (ERCP) and endoscopic retrograde biliary drainage (ERBD) are important treatment methods to treat obstructive jaundice. They can restore the enterohepatic circulation, block inflammatory reactions, and improve the patient prognosis. However, plastic biliary stents often become clogged 2-3 months after implantation, with the sediment primarily composed of pathogenic microorganisms and biliary sludge..$^{7-13}$ The reason may be related to the diameter of biliary stents, rough bracket and bile interface, change in biliary fluid dynamics, and bacterial growth.

Teflon is the most widely used material in clinically available plastic biliary stents. We prepared AgNP-coated biliary stents using a chemical oxidation-reduction 
method and compared the antisedimentation behavior of AgNP-coated and Teflon biliary stents in an experimental obstructive jaundice model in beagles. The aim was to evaluate the antagonism of AgNP coating to sedimentation.

\section{Materials and methods}

Preparation of AgNP-coated biliary stent using chemical oxidation-reduction method

Silver-ammonia complex ion reduction was used to prepare the AgNP coatings with sodium-naphthalene as the roughing solution. An 8.5 Fr Teflon biliary stent with a length of $12 \mathrm{~cm}$ (COOK, Bloomington, IN, USA) was used as the host material
(Figure 1A), and was cut into $3 \mathrm{~cm}$ lengths for use in the experimental model. We began by removing surface grease by ultrasonic oscillation and then soaking the Teflon biliary stent in a sodium-naphthalene solution for roughening and $\mathrm{SnCl}_{2}$ for sensitization. Finally, AgNPs were deposited on the Teflon stent surface by the oxidation-reduction method to prepare the coating (Figure 1B). Scanning electron microscopy (SEM, JSM-6700F, JEOL Ltd, Tokyo, Japan) and energy dispersive spectrometry (EDS, Oxford INCA X sight, Oxford Company, Oxfordshire, UK) were used to characterize the coating morphology and determine the optimal dose proportion; the optimal concentration of the silver-ammonia solution was found to be $\mathrm{AgNO}_{3} 0.3 \mathrm{~g}+\mathrm{H}_{2} \mathrm{O} 15 \mathrm{~mL}+\mathrm{NH}_{3} \cdot \mathrm{H}_{2} \mathrm{O} 1 \mathrm{~mL}+$ $\mathrm{H}_{2} \mathrm{O} 9 \mathrm{~mL}$. The optimal sensitizing solution was found to be $\mathrm{SnCl}_{2} 0.5 \mathrm{~g}+\mathrm{HCl} 2 \mathrm{~mL}+\mathrm{H}_{2} \mathrm{O} 48 \mathrm{~mL}+\mathrm{Sn}$.

B

A

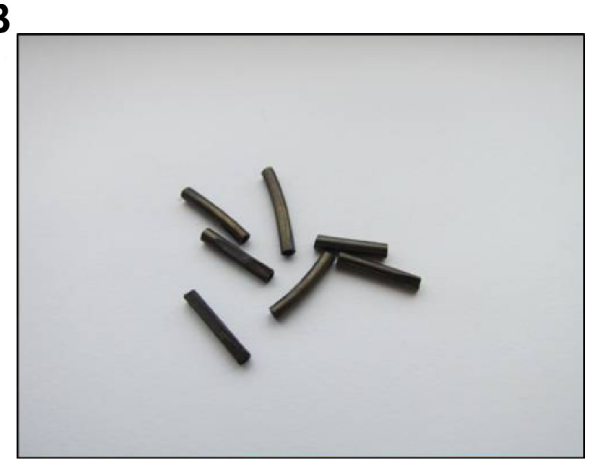

C
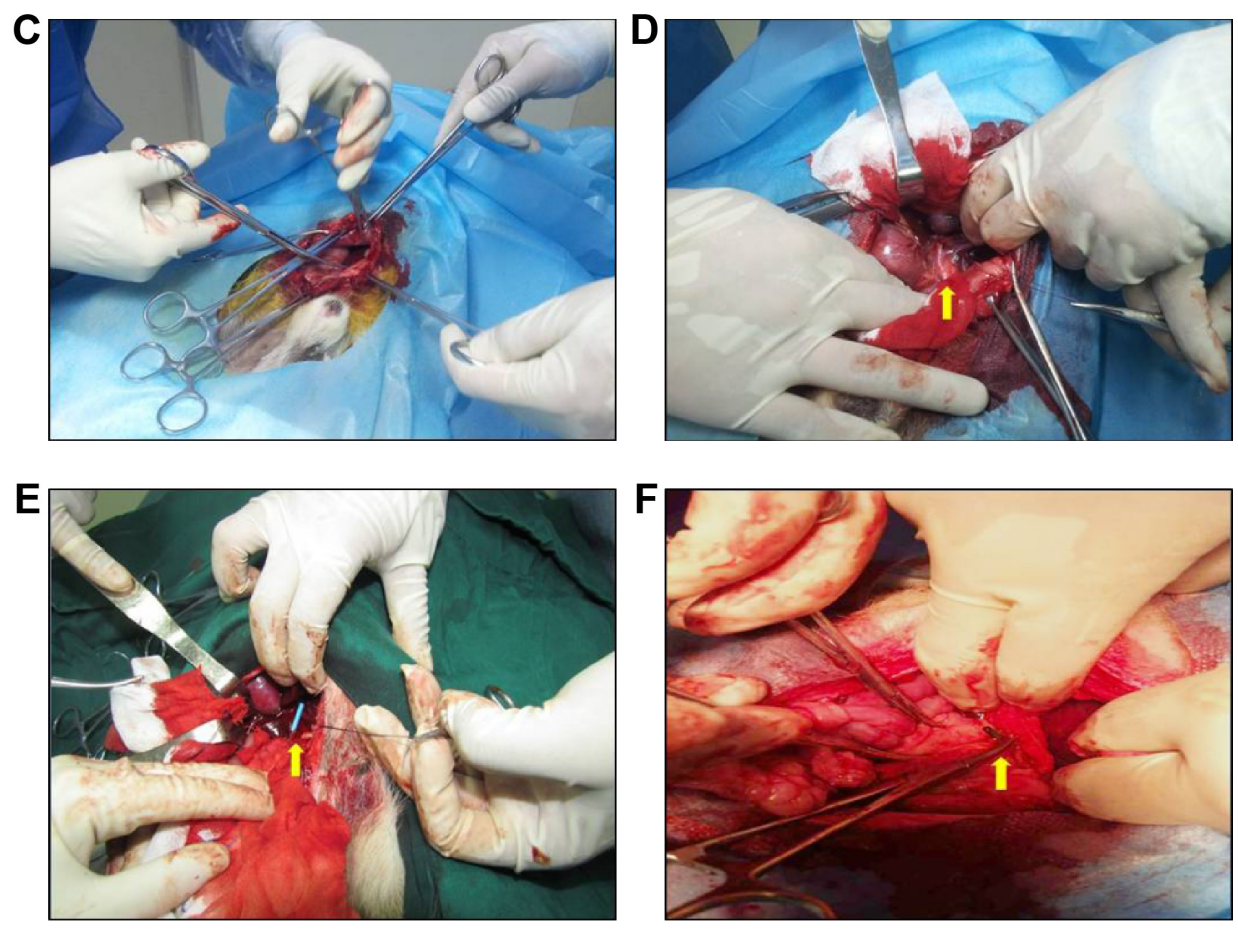

Figure I AgNP-coated biliary stents were produced and implanted in dogs in an experimental model of obstructive jaundice.

Notes: Teflon (12 cm, $8.5 \mathrm{Fr})$ and AgNP-coated $(3 \mathrm{~cm}, 8.5 \mathrm{Fr}$ ) biliary stents were produced by a chemical oxidation-reduction method $(\mathbf{A})$ and $(\mathbf{B})$. Modeling procedure involving opening the abdominal cavity and CBD ligation (C). Yellow arrow indicates CBD (D). Biliary stent placement: Teflon (blue) and AgNP-coated (black) biliary stents. Yellow arrow indicates CBD (E) and (F).

Abbreviations: AgNP, silver nanoparticle; $C B D$, common bile duct. 


\section{Canine obstructive jaundice model}

Twelve healthy male and female beagle dogs weighing $10-13 \mathrm{~kg}$ were selected for use in the experimental obstructive jaundice model. The dogs were fasted for 6 hours before surgery and anesthetized by intravenous administration of $3 \%$ pentobarbital sodium via the cephalic vein in a front leg. An $8-10 \mathrm{~cm}$ midline abdominal incision (Figure 1C) was made to expose the serosa of the hepatoduodenal ligament above the superior border of the duodenum. The common bile duct (CBD) was then separated and ligated with a $2-0$ suture (Figure 1D). This study was approved by the medical experiments ethics committee of Shandong Provincial Qianfoshan Hospital affiliated to Shandong University. The institutional guidelines for this study regarding the animals welfare are as follows: Laboratory Animal Welfare and Animal Experimental Science, Science Press, Version 1 (June 1, 2011), ISBN: 9787030311757.

\section{Controlled study of sediment antagonism by AgNP-coated biliary stents}

Animals were randomly assigned to experimental AgNPcoated $(n=6)$ or control Teflon biliary stents $(n=6)$ groups
3 days after modeling. Experimental and control animals did not differ in liver function and inflammatory index. All the statistical tests were conducted using $t$-test, $\alpha=0.05$ was the inspection level, and $P<0.05$ was considered as statistically significant. All computations were performed with SPSS Complex Samples ${ }^{\mathrm{TM}} 17.0$ software (SPSS Inc., Chicago, IL, USA).

During the second surgical procedure, we found cholestasis in the beagle livers, and expansion of the CBD above the ligature. The anterior wall of the CBD was cut open and a $3 \mathrm{~cm}$ AgNP-coated or Teflon biliary stent was positioned (Figure $1 \mathrm{E}$ and $\mathrm{F}$ ), ensuring that it passed through the ligature and removed the bile duct obstruction. After 21 days, the abdominal cavity of surviving animals was opened again to remove the stents. The entire CBD including the biliary stent, artificial narrowing in the area of ligature, ampulla, and the duodenum are shown in Figure 2A-C. A bile duct stone observed after extraction of a Teflon biliary stent in a control animal is shown in Figure 2D.

Biliary stents were cut into pieces of suitable size for SEM, cleaned, and critical-point dried. The morphology of the AgNP-coating and biliary stent sediment was observed
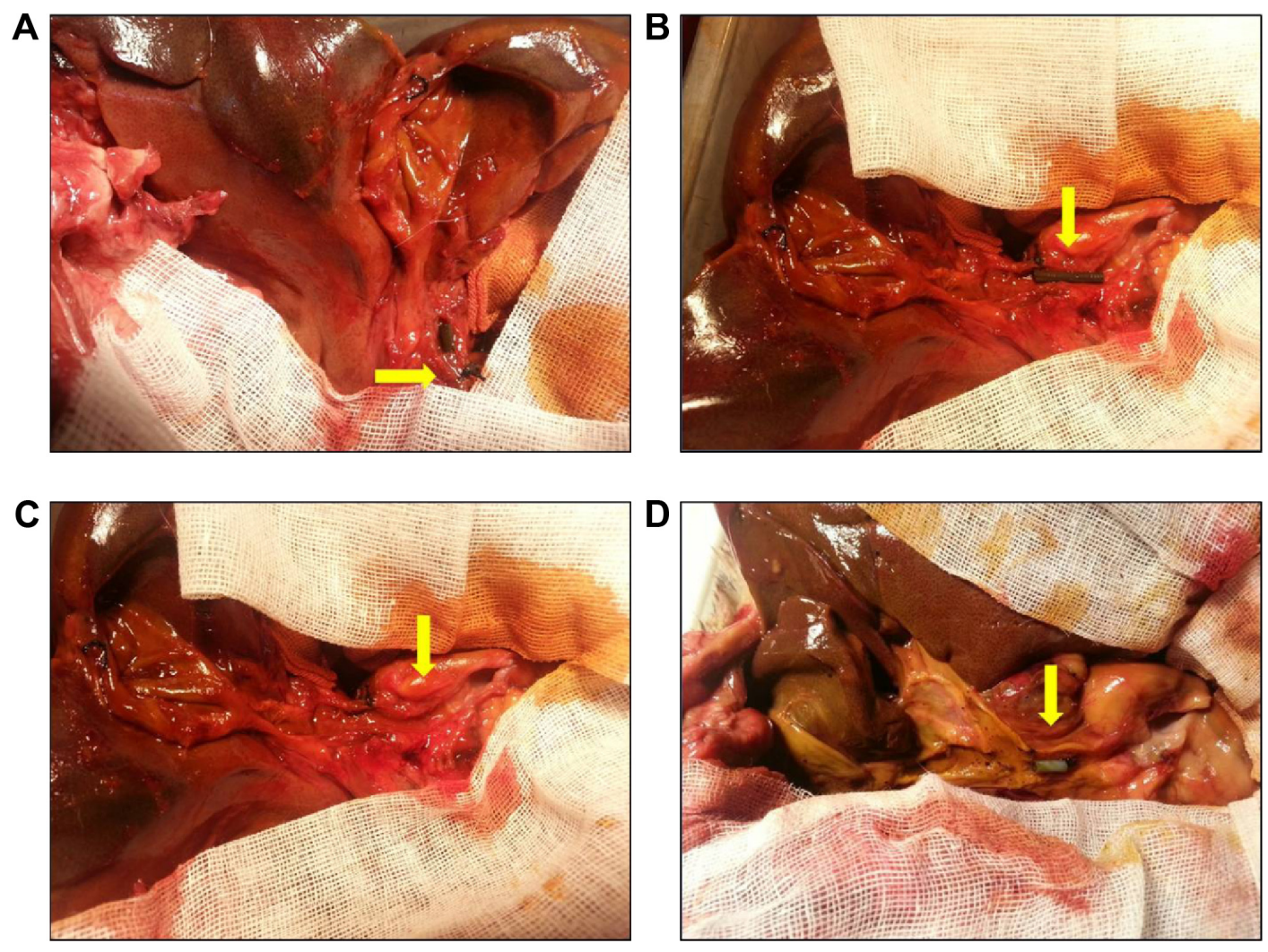

Figure 2 Open abdominal cavity of an experimental animal.

Notes: Yellow arrows point to the AgNP-coated biliary stent and CBD ligation suture (A); AgNP-coated biliary stent, with the left end in the CBD, the right end in the duodenum, and the artificial narrowing formed by the ligature in the middle (B); the ampulla structure (C); the location of CBD stones in an animal with a Teflon biliary stent (D). Abbreviations: AgNP, silver nanoparticle; $C B D$, common bile duct. 
by SEM $(3.0-5.0 \mathrm{kV}$, working distance $=8 \mathrm{~mm})$ and $\mathrm{EDS}$ before and after animal experiments.

After stents were extracted from the experimental animals, sediment was removed from biliary stents, ground, and cleaned ultrasonically in absolute alcohol and in deionized water. Following centrifugation at 3,500 rpm, sediment was resuspended in absolute alcohol and samples were collected on 200 mesh copper grids and air dried for transmission electron microscopy (TEM; 100 kV; JEM-101, JEOL Ltd).

Small amounts of sediment were prepared for Fouriertransform infrared (FTIR) spectroscopy by mixing with potassium bromide (1:50), grinding in an agate mortar, and pelleting into slices. Sediment composition was compared with that of previously analyzed biliary stones.

\section{Results}

\section{Experimental characteristics of animals after modeling}

After establishing the experimental obstructive jaundice model, there were no significant differences in alanine aminotransferase, aspartate aminotransferase, total bilirubin (TBIL), or direct bilirubin (DBIL) in animals with AgNPcoated and Teflon biliary stents $(P>0.05$, Table 1$)$. There were also no differences in the concentrations of tumor necrosis factor $\alpha$ and interleukin-6 ( $P>0.05$, Table 2$)$. General data of beagle canine model are listed in Table S1.

\section{Weight of biliary stent sediment}

The weight of biliary sediment collected from Teflon stents was significantly greater than that of the sediment collected from AgNP-coated stents $(P<0.05$, Table 3$)$.

\section{SEM morphology of AgNP stent coating}

Different concentrations of silver-ammonia solution produced AgNP coatings of differing thickness, which increased with the concentration of the silver-ammonia solution. We found the optimum reaction temperature and silver-ammonia

Table I Liver function in experimental animals after modeling $(\mathrm{n}=6, \bar{x} \pm s)$

\begin{tabular}{|c|c|c|c|c|}
\hline Group & $\begin{array}{l}\text { ALT } \\
(\mathrm{U} / \mathrm{L})\end{array}$ & $\begin{array}{l}\text { AST } \\
\text { (U/L) }\end{array}$ & $\begin{array}{l}\text { TBIL } \\
\text { ( } \mu \mathrm{mol} / \mathrm{L})\end{array}$ & $\begin{array}{l}\text { DBIL } \\
(\mu \mathrm{mol} / \mathrm{L})\end{array}$ \\
\hline Teflon & $176.83 \pm 19.69 *$ & $270.00 \pm 25.78 *$ & $77.76 \pm 2.26 *$ & $69.47 \pm 6.80$ * \\
\hline AgNPs & $172.00 \pm 22.78$ & $293.33 \pm 27.35$ & $78.17 \pm 6.70$ & $73.45 \pm 6.58$ \\
\hline$P$-value & 0.70 & 0.16 & 0.92 & 0.33 \\
\hline
\end{tabular}

Table 2 Concentration of TNF- $\alpha$ and IL- 6 of experimental animal after modeling $(n=6, \bar{x} \pm s)$

\begin{tabular}{lll}
\hline Group & TNF- $\alpha(\mathrm{pg} / \mathrm{mL})$ & IL-6 $(\mathrm{pg} / \mathrm{mL})$ \\
\hline Teflon & $64.05 \pm 2.49^{*}$ & $322.60 \pm 22.92^{*}$ \\
AgNPs & $66.72 \pm 2.84$ & $325.93 \pm 19.38$ \\
$P$-value & 0.12 & 0.79 \\
\hline
\end{tabular}

Note: $* P>0.05$, there were no statistical differences between both groups after modeling.

Abbreviations: AgNPs, silver nanoparticles; IL-6, interleukin-6; TNF- $\alpha$, tumor necrosis factor $\alpha$.

solution concentration through repeated trials. The boundary between the AgNP coating and Teflon biliary stent was clearly observed by SEM, permitting easy measurement of the AgNP coating thickness (Figure 3A-C). The thickness of AgNP coating ranged from 1.5 to $6.0 \mu \mathrm{m}$.

\section{SEM characterization of biliary stent sediment}

SEM revealed that the sediment layer that accumulated on Teflon biliary stents was thicker than that on AgNP-coated stents (Figure 4A and B). The sediment on Teflon stents had a more regular structure than the sediment on AgNP-coated stents. At high magnification (Figure $4 \mathrm{C}$ and D), the surface of Teflon stent sediment was relatively flat and appeared more compact than the sediment on AgNP-coated stent, which had a loose, irregular structure with many bumps and angles.

\section{Composition of AgNP coating before and after animal experiments}

Energy dispersive X-ray analysis confirmed the stability of Ag in the AgNP coating, with little change after animal experiment (Figure 5).

\section{TEM morphology of biliary stent sediment}

TEM revealed that, at the same magnification, sediment from Teflon stent had a denser appearance than sediment from AgNP-coated stents (Figure 6A and B) and had a smooth, flat surface. Sediment from AgNP-coated stents had an irregular surface and appeared to be less compact (Figure 6C and D).

Table 3 Biliary stent sediment weight $(n=6, \bar{x} \pm s)$

\begin{tabular}{ll}
\hline Group & Sediment weight $\mathbf{( g )}$ \\
\hline Teflon & $0.325 \pm 0.026^{*}$ \\
AgNPs & $0.261 \pm 0.045$ \\
$P$-value & 0.017 \\
\hline
\end{tabular}

Note: $* P<0.05$, there were statistical differences between both groups after modeling.

Abbreviation: AgNPs, silver nanoparticles. 

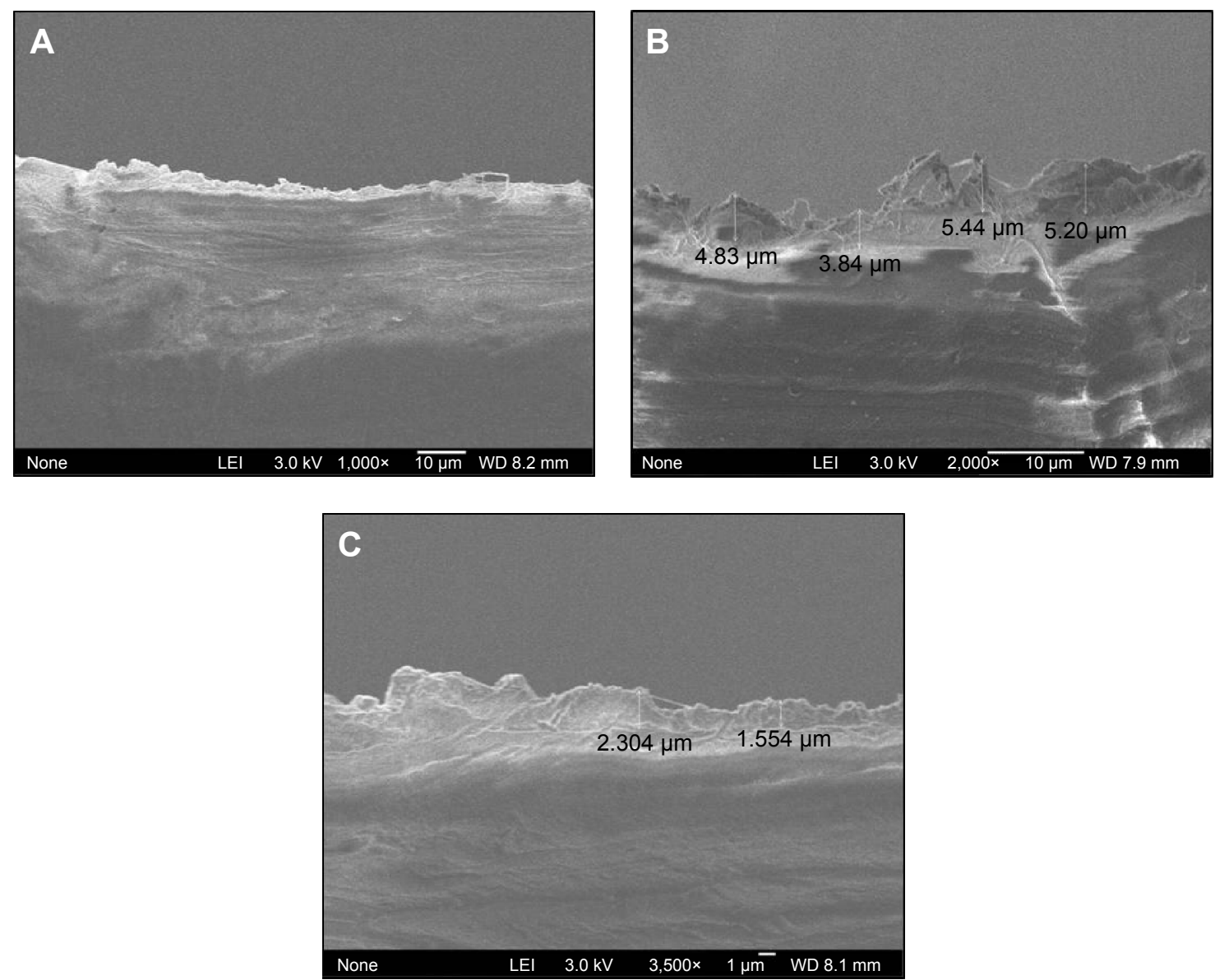

Figure 3 Morphology of AgNP-coated stents observed by SEM.

Notes: (A) AgNP-coated and Teflon biliary stents clearly show host material boundaries (I,000×). (B) AgNP coating with thickness of 3.84-5.44 $\mu \mathrm{m}(2,000 \times)$. (C) AgNP coating with thickness of $1.554-2.304 \mu \mathrm{m}(3,500 \times)$.

Abbreviations: AgNP, silver nanoparticle; SEM, scanning electron microscopy.

\section{FTIR spectroscopy of stent sediment}

FTIR absorption spectra (Figure 7) indicated that the biliary stent sediment included bilirubin (absorption peaks at $\left.3,411,2,915,1,592,1,466,1,250,699 \mathrm{~cm}^{-1}\right)$, cholesterol $\left(2,868,1,377,1,057 \mathrm{~cm}^{-1}\right)$, bile acids $\left(1,645,613 \mathrm{~cm}^{-1}\right)$, proteins $\left(3,400,1,235 \mathrm{~cm}^{-1}\right)$, and bilirubin calcium salts $\left(1,627\right.$ and $\left.1,573 \mathrm{~cm}^{-1}\right)$. The sediment compositions were confirmed by comparing the absorption peaks and vibration wave number ranges obtained with human mixed-type biliary stones, which were as follows: bilirubin $(3,411,2,915$, 1691-699 $\left.\mathrm{cm}^{-1}\right)$, cholesterol $(3,431,2,933,2,867-1,466$, $\left.1,377-1,056 \mathrm{~cm}^{-1}\right)$, bile acids $\left(3,416,1,645,1,563-613 \mathrm{~cm}^{-1}\right)$, proteins $\left(3,400,2,955,2,915-1,235 \mathrm{~cm}^{-1}\right)$, and bilirubin calcium salts $\left(1,696,1,663,1,627,1,573 \mathrm{~cm}^{-1}\right)$.

\section{Discussion}

The main cause of biliary restenosis is the formation of bacterial biofilms ${ }^{14,15}$ that combine with other substances in bile form "biliary mud", which accumulates and eventually blocks the stent. There is a need for new types of biliary stents with a combined effect of bacteriostasis and resistance to deposition of bile sediment. This preliminary study describes the morphological characteristics and sediment resistance of a novel AgNP-coated stent.

We prepared AgNP-coated biliary stents by a chemical oxidation-reduction method, and used Teflon as a matrix material. Dilute nitric acid was used as the coarsening agent, naphthalene was used as dispersant, $\mathrm{SnCl}_{2} \cdot 2 \mathrm{H}_{2} \mathrm{O}$ was the reductant, silver nitrate was the raw material, and ammonia $\left(\mathrm{NH}_{3} \cdot \mathrm{H}_{2} \mathrm{O}\right)$ was the buffer solution. $\mathrm{NH}_{3} \cdot \mathrm{H}_{2} \mathrm{O}$ is a weakly alkaline buffer, ensuring uniform attachment of $\mathrm{Ag}^{+}$to the inside and outside walls of the stent. In both humans and animals, bile is a weakly alkaline liquid; we thus prepared the AgNP-coated biliary stents in a weakly alkaline system to mimic the physiological environment in the hope of achieving stable performance.

Many types of biliary stents are used clinically for endoscopic treatment of benign and malignant obstructive 

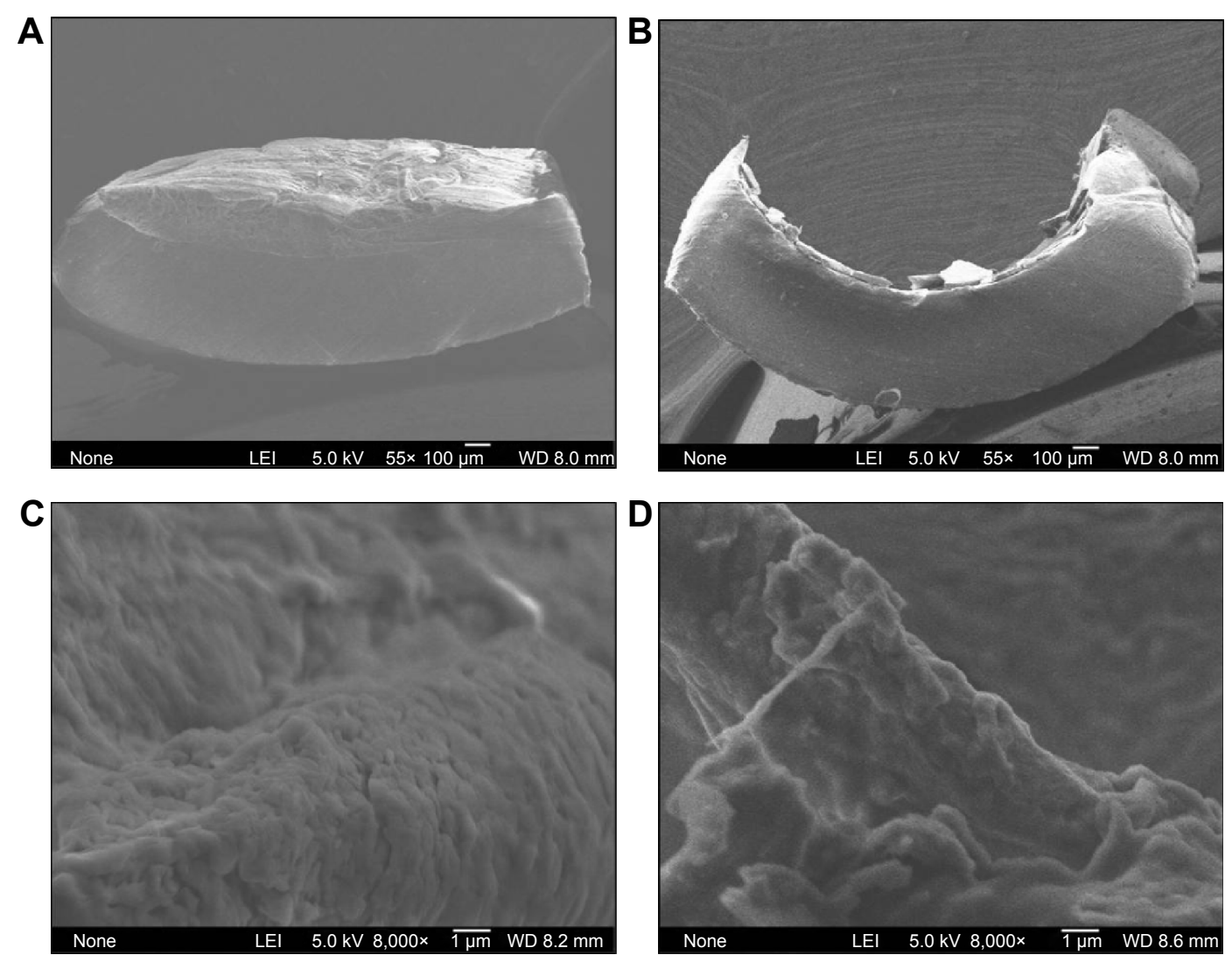

Figure 4 SEM of sediment from both types of stent.

Notes: (A) Teflon biliary stent sediment (55×). (B) AgNP-coated biliary stent sediment (55×). (C) Teflon biliary stent sediment with compact structure (8,000×). (D) AgNPcoated biliary stent sediment with loose structure $(8,000 \times)$.

Abbreviations: AgNP, silver nanoparticle; SEM, scanning electron microscopy.
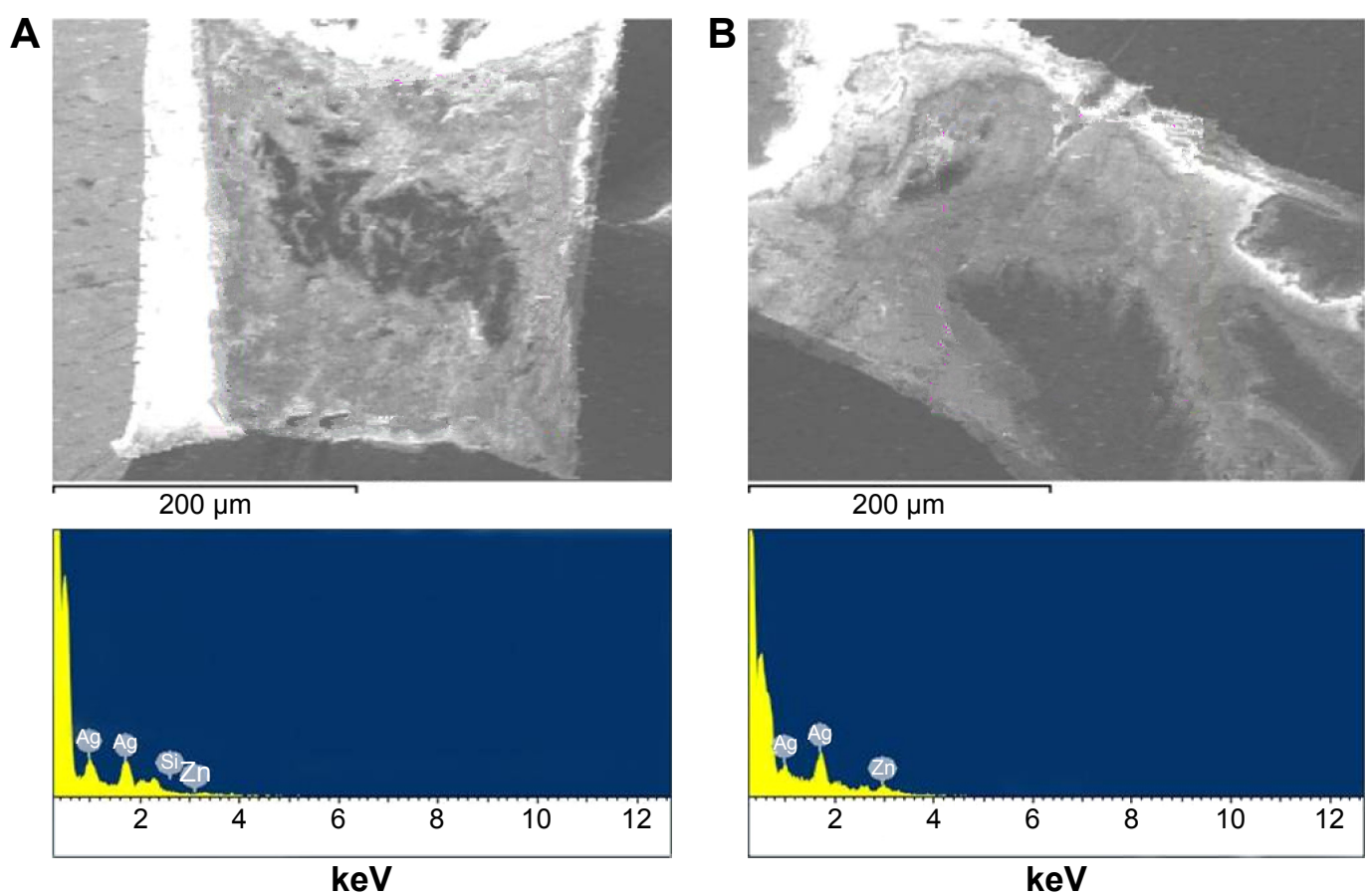

Figure 5 EDXA results before and after the contrast experiments show that the main metal component was Ag mixed with $\mathrm{Si}$ and $\mathrm{Zn}$ impurities.

Notes: The horizontal axis shows keV; the vertical axis shows the metal content. (A) AgNP-coated biliary stent before animal experiments with Ag as the main coating component. (B) AgNP-coated biliary stent after animal experiments with $\mathrm{Ag}$ as the main coating component.

Abbreviations: AgNP, silver nanoparticle; EDXA, energy dispersive $X$-ray analysis. 

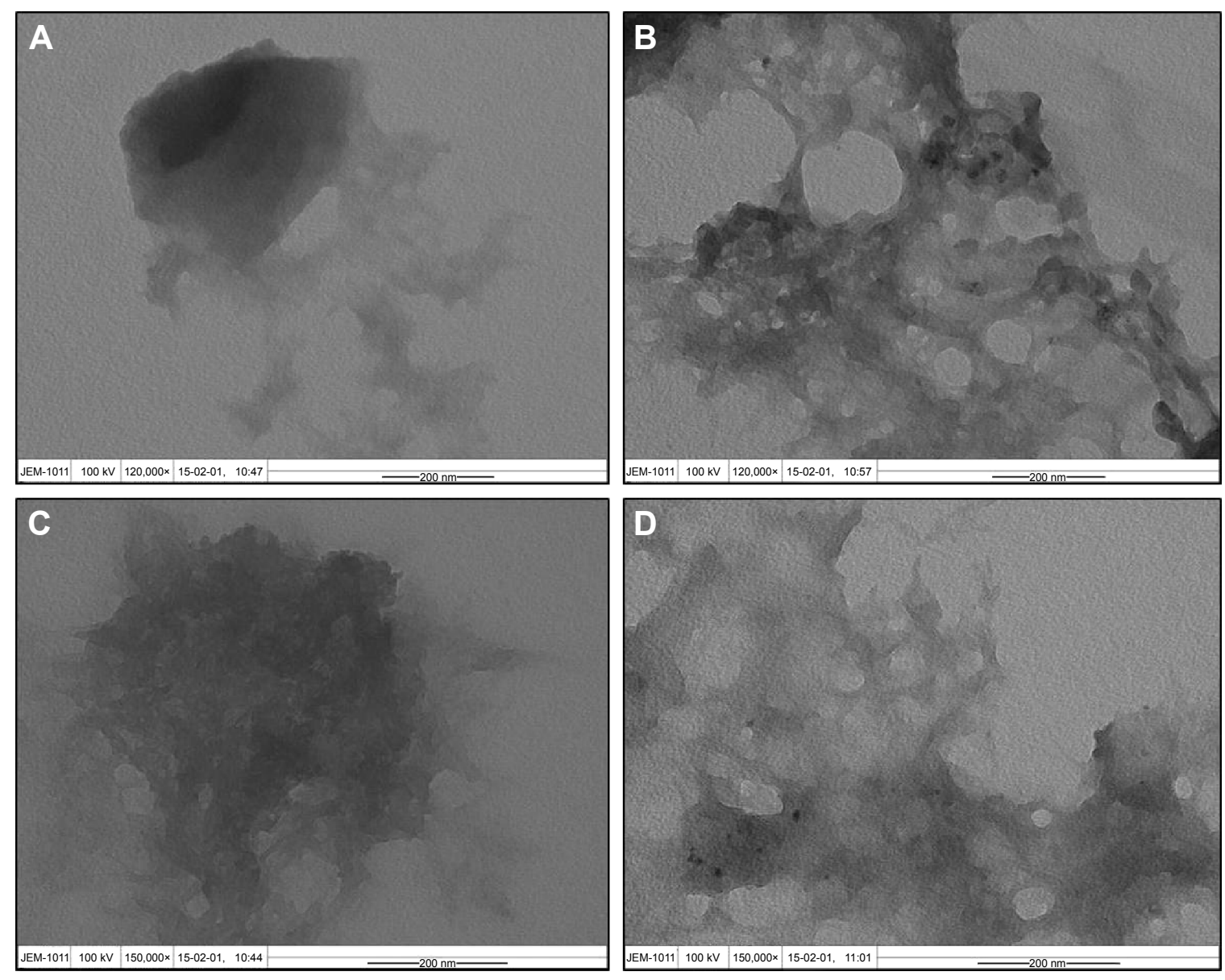

Figure 6 TEM of stent sediments in both types of stent.

Notes: (A) Teflon biliary stent sediment (I20,000×). (B) AgNP-coated biliary stent sediment (I20,000x). (C) Teflon biliary stent sediment (I50,000x). (D) AgNP-coated biliary stent sediment $(150,000 \times)$.

Abbreviations: AgNP, silver nanoparticle; TEM, transmission electron microscopy.

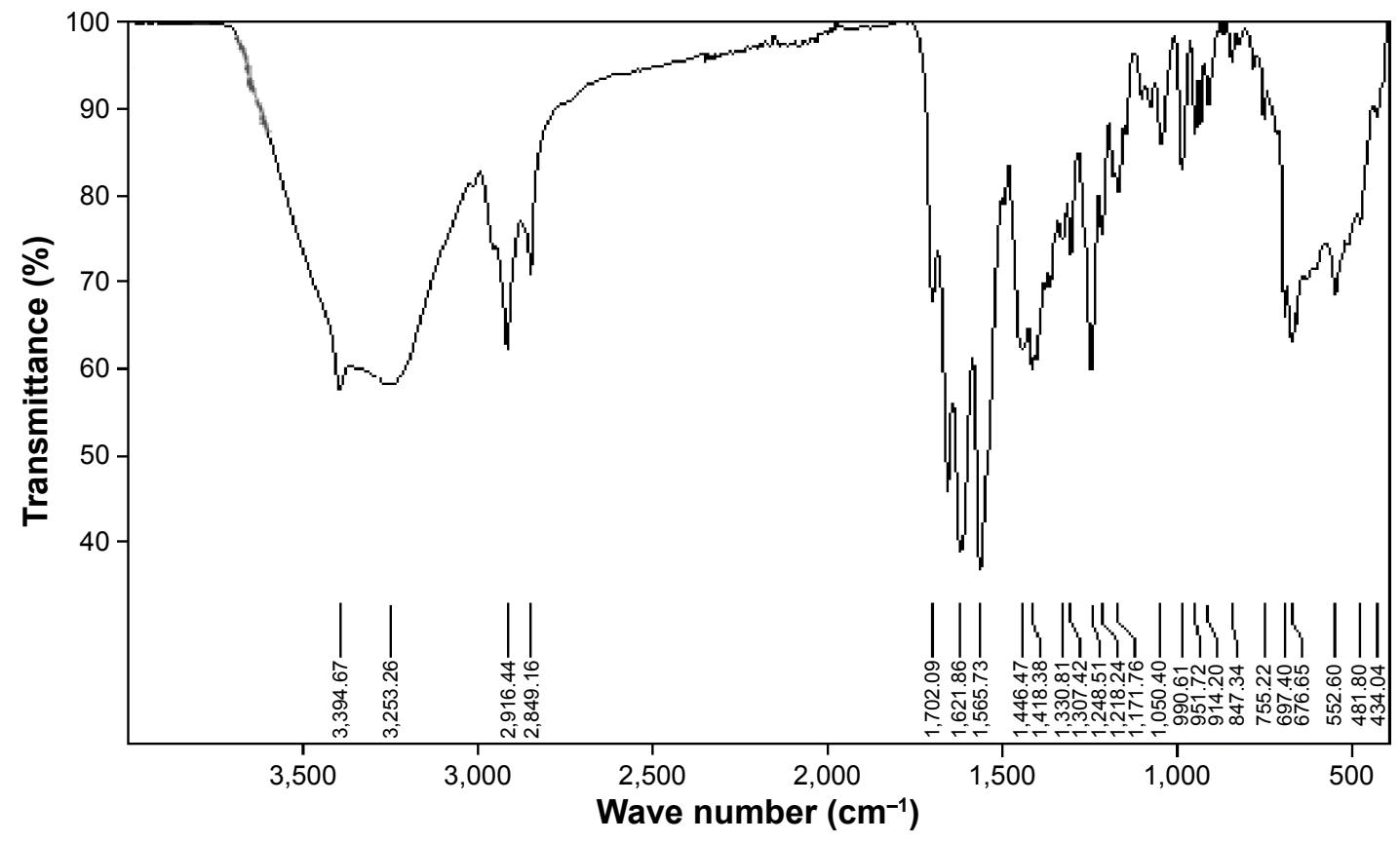

Figure $\mathbf{7}$ Infrared spectrum analysis of biliary stent sediment. 
jaundice. ${ }^{16-20}$ The applications include ERCP, endoscopic sphincterotomy (EST), ${ }^{21}$ endoscopic nasobiliary drainage, ${ }^{22,23}$ and ERBD. ${ }^{24}$ Endoscopic procedures have the obvious advantages of safety, minimal invasiveness, convenience, few postprocedural complications, and good tolerance. They are especially advantageous for aged or weak patients who cannot tolerate surgery.

Stent obstruction, retrograde infection, duct wall inflammation, bleeding, perforation, and stent displacement are common complications of ERCP. Benign biliary stricture can be caused by bile duct inflammation, a history of bile duct surgery, sclerosing cholangitis, pyogenic cholangitis, and chronic pancreatitis. Stent placement is also an ideal treatment for bile duct anastomotic stenosis following liver transplantation. ${ }^{25} \mathrm{With}$ the increasing use of liver and gallbladder surgery, iatrogenic bile duct injury is increasing in clinical importance, and endoscopic treatment might become the first treatment of choice. Malignant biliary obstruction may be caused by compression of malignant tumors or lymphatic metastasis of digestive tract tumors. Biliary stent placement can significantly relieve malignant obstructive jaundice and can also relieve jaundice to improve perisurgical safety. ${ }^{26}$

Coated and noncoated metal, biodegradable, and drugeluting biliary stents, as well as stents coated with radioactive particles are all in clinical use. The length, diameter, number, material, type, placement method, and disease should all be considered when choosing a suitable biliary stent. The stent type should be selected according to the disease, and in case of benign diseases, noncoated metal biliary stents should be avoided in favor of plastic or removable coated metal stents. The appropriate stent length and diameter depend on the extent of drainage and degree of stenosis, especially in cases of high bile duct obstruction, such as hilar cholangiocarcinoma.

The clinical evidence shows that plastic biliary stents can lead to edema of the CBD. Sung et $\mathrm{al}^{27}$ found that implantation of stents with one end positioned in the duodenal cavity could result in dysfunction of the sphincter of the ampulla. Reflux of pathogenic bacteria from the duodenal cavity into the bile duct along with intestinal juice increased the chance of retrograde biliary infection and stent blockage. Slivka and Carr-Locke ${ }^{28}$ found that $20 \%-30 \%$ of plastic stents became obstructed within 3 months of placement, and $70 \%$ became obstructed in 6 months.

Reducing the formation of stent sediment, bacterial adhesion, and biofilm formation are key targets in the antagonism of biliary stent clogging mechanisms. If clogging can be reduced, significant improvements can be had in 1) bile flow rate, ${ }^{29}$ 2) inhibition of bacterial adhesion and biofilm formation; $;{ }^{30} 3$ ) change in bile composition; ${ }^{31}$ and 4) materials, composition, and properties of biliary stents. ${ }^{32}$ The AgNPcoated stents were antagonistic to sedimentation, as shown by the reduced thickness of the sediment adhering to the stent.

We established a satisfactory experimental obstructive jaundice animal model. Experimental variables were constant, and the in vivo environment was stabile, all of which contributed to the reliability of the data. After modeling, the enterohepatic circulation of experimental animals was blocked, which quickly resulted in jaundice. Index assays indicated an increase in TBIL- and DBIL-typical obstructive jaundice. We used Teflon and AgNP-coated biliary stents to relieve biliary obstruction to model the human biliary obstruction environment before and after stent placement. SEM and TEM showed that the AgNP coating antagonized stent sediments. The results obtained with this experimental model can provide data for the further development of AgNP-coated stent in basic research and for future clinical applications.

Both SEM and TEM confirmed that the sediment layer that adhered to AgNP-coated stents was thinner than that on the Teflon stents. The AgNP coating thus increased antagonism to sediments. Stones also developed in the bile duct of animals with Teflon stents but not in those with the AgNPcoated stents. Extensive investigation of the time course of this reaction is needed to determine the reason for secondary stone formation in such a short interval. We have already observed this kind of stone formation in the clinic. Some patients with choledocholithiasis and confirmed absence of residual biliary tract stones by t-tube cholangiography after ERCP + EST or laparoscopic cholecystectomy plus CBD exploration developed recurrent CBD stones within 3 months. Whether the mechanism of stone formation is the same in all patients needs to be confirmed in follow-up studies.

van Berkel et $\mathrm{al}^{33}$ used confocal laser scanning microscopy and SEM to evaluate the performance of two polythene and hydrophilic polyurethane polymer-coated stents. After 3 months, they found homogeneous tissue on the surface of the stents that consisted of biofilms consisting of living and dead bacteria. The stent lumen was full of free floating bacterial colonies and crystalline material surrounded by foliated mucus structures. This open-mesh fibrous structure included food due to duodenal reflux and was considered to be responsible for clogging.

The composition of stent sediment was analyzed by FTIR spectroscopy, which showed that it contained bilirubin, 
bile acid, calcium bile salts, and other substances similar to hybrid calculi. Costa et $\mathrm{al}^{34}$ analyzed the chemical composition of biliary stent sediments and found that they comprised calcium, bilirubin, and other components, such as protein and unconjugated bilirubin, which was confirmed in our study.

Successful modeling of clogging that follows placement of biliary stents in appropriate animal models is highly significant. Such experimental systems permit systematic research on the influence of different components on sedimentation and search for a more suitable bile duct stent composite materials. Many solutions have been proposed to solve the stent clogging phenomenon, such as increasing the stent diameter, removing flanks, changing the placement method, and changing the composition of the stent surface. Each has a clinical effect, but none have proven ideal. ${ }^{35,36}$

\section{Conclusion}

In this experimental animal model of obstructive jaundice, we found that coating stents with AgNPs was antagonistic to sediment. This novel type of composite bile duct stent effectively reversed the obstruction symptoms and may prolong stent life and delay recurrence of obstruction.

In clinical use, clogging of plastic biliary stents is a common occurrence. Prolonging the time for clogging to occur has significant clinical benefit for patients. Our preliminary results with AgNP-coated stents in this experimental model were positive. With ongoing research, we believe that we will succeed in developing biliary stents with antagonistic properties to sediment deposition.

\section{Acknowledgments}

This study was supported by grants from Natural Science Foundation of Shandong Province (ZR2012HM029), Science and Technology Development Plan of Shandong Province (2011GSF11836), and Science and Technology Development Plan of Jinan City (20140821).

\section{Disclosure}

The authors report no conflicts of interest in this work.

\section{References}

1. Hu Q, Liang B, Sun Y, et al. Preparation of bufalin-loaded pluronic polyetherimide nanoparticles, cellular uptake, distribution, and effect on colorectal cancer. Int J Nanomedicine. 2014;9:4035-4041.

2. Park SJ, Taton TA, Mirkin CA. Array-based electrical detection of DNA with nanoparticle probes. Science. 2002;295(5559):1503-1506.

3. Wang G, Jin F, Dai N, et al. Signal-enhanced electro chemiluminescence immunosensor based on synergistic catalysis of nicotinamide adenine dinucleotide hydride and silver nanoparticles. Anal Biochem. 2012; 422(1):7-13.
4. Alt V, Bechert T, Steinrucke P, et al. Nanoparticulate silver. A new antimicrobial substance for bone cement. Orthopade. 2004;33(8): 885-892.

5. Muangman P, Chuntrasakul C, Silthram S, et al. Comparison of efficacy of $1 \%$ silver sulfadiazine and Acticoat for treatment of partial-thickness burn wounds. J Med Assoc Thai. 2006;89(7):953-958.

6. Zhang P, Wang H, Zhang X, et al. Graphene film doped with silver nanoparticles: self-assembly formation, structural characterizations, antibacterial ability, and biocompatibility. Biomater Sci. 2015;3(6): 852-860.

7. Donlan RM, Costerton JW. Biofilms: survival mechanisms of clinically relevant microorganisms. Clin Microbiol Rev. 2002;15(2):167-193.

8. Cvitkovitch DG, Li YH, Ellen RP. Quorum sensing and biofilm formation in Streptococcal infections. J Clin Invest. 2003;112(11):1626-1632.

9. Leung JW, Liu Y, Chan RC, et al. Early attachment of anaerobic bacteria may play an important role in biliary stent blockage. Gastrointest Endosc. 2000;52(6):725-729.

10. Leung JW, Ling TK, Kung JL, et al. The role of bacteria in the blockage of biliary stents. Gastrointest Endosc. 1988;34(1):19-22.

11. Provansal-Cheylan M, Bernard JP, Mariani A, et al. Occluded pancreatic endoprostheses-analysis of the clogging material. Endoscopy. 1989; 21(2):63-69.

12. Maetani I, Ukita $\mathrm{T}$, Inoue $\mathrm{H}$, et al. Microwave coagulation versus insertion of a second stent for occluded biliary metal stent. Hepatogastroenterology. 2001;48(41):1279-1283.

13. Yang YL, Shi LJ, Lin MJ, et al. Clinical analysis and significance of cholangiography for biliary cast/stone after orthotopic liver transplantation. J Nanosci Nanotechnol. 2013;13(1):171-177.

14. Hoffman BJ, Cunningham JT, Marsh WH, et al. An in vitro comparison of biofilm formation on various biliary stent materials. Gastrointest Endosc. 1994;40(5):581-583.

15. Kiran MD, Giacometti A, Cirioni O, et al. Suppression of biofilm related, device-associated infections by staphylococcal quorum sensing inhibitors. Int J Artif Organs. 2008;31(9):761-770.

16. Tesdal IK, Roeren T, Weiss $C$, et al. Metallic stents for treatment of benign biliary obstruction: a long-term study comparing different stents. J Vasc Interv Radiol. 2005;16(11):1479-1487.

17. Perri V, Familiari P, Tringali A. Plastic biliary stents for benign biliary diseases. Gastrointest Endosc Clin N Am. 2011;21(3):405-433.

18. Piñol V, Castells A, Bordas JM, et al. Percutaneous self-expanding metal stents versus endoscopic polyethylene endoprostheses for treating malignant biliary obstruction: randomized clinical trial. Radiology. 2002; 225(1):27-34.

19. Bakhru MR, Kahaleh M. Expandable metal stents for benign biliary disease. Gastrointest Endosc Clin N Am. 2011;21(3):447-462.

20. Prachayakul V, Aswakul P. Feasibility and safety of using Soehendra stent retriever as a new technique for biliary access in endoscopic ultrasound-guided biliary drainage. World J Gastroenterol. 2015;21(9): 2725-2730.

21. Bose SM, Mazumdar A, Singh V. The role of endoscopic procedures in the management of postcholecystectomy and posttraumatic biliary leak. Surg Today. 2001;31(1):45-50.

22. Elmi F, Silverman WB. Nasobiliary tube management of postcholecystectomy bile leakage. J Clin Gastroenterol. 2005;39(5):441-444.

23. Park JS, Kim MH, Lee SK, et al. Efficacy of endoscopic and percutaneous treatments for biliary complications after cadaveric and living donor liver transplantation. Gastrointest Endosc. 2003;57(1): $78-85$.

24. Katsinelos P, Kountouras J, Paroutoglou Q, et al. A comparative study of 10-Fr vs 7-Fr straight plastic stents in the treatment of postcholecystectomy bile leak. Surg Endosc. 2008;22(1):101-106.

25. Zhang YC, Qu EZ, Ren J, et al. New diagnosis and therapy model for ischemic-type biliary lesions following liver transplantation - a retrospective cohort study. PLoS One. 2014;9(9):e105795.

26. van der Gaag NA, Rauws EA, van Eijck CH, et al. Preoperative biliary drainage for cancer of the head of the pancreas. N Engl J Med. 2010; 362(2):129-137. 
27. Sung JY, Leung JW, Shaffer EA, et al. Ascending infection of the biliary tract after surgical sphincterotomy and biliary stenting. J Gastroenterol Hepatol. 1992;7(3):240-245.

28. Slivka A, Carr-Locke DL. Therapeutic biliary endoscopy. Endoscopy. 1992;24(1-2):100-119.

29. Zhang H, Tsang TK, Pollack J, et al. Evaluation of role of bile flow patterns in process of in vitro stent occlusion. Dig Dis Sci. 2002;47(12): 2691-2695.

30. Rerknimitr R, Fogel EL, Kalayci C, et al. Microbiology of bile in patients with cholangitis or cholestasis with and without plastic biliary endoprosthesis. Gastrointest Endosc. 2002;56(6):885-889.

31. Zhang H, Tsang TK, Jack CA, et al. Role of bile mucin in bacterial adherence to biliary stents. J Lab Clin Med. 2002;139(1):28-34.

32. Tringali A, Mutignani M, Perri V, et al. A prospective, randomized multicenter trial comparing DoubleLayer and polyethylene stents for malignant distal. Endoscopy. 2003;35(12):992-997.
33. van Berkel AM, van Marle J, Groen AK, et al. Mechanisms of biliary stent clogging: confocal laser scanning and scanning electron microscopy. Endoscopy. 2005;37(8):729-734.

34. Costa L, Bracco P, Vada S, et al. A chemical analysis of the clogging process of polymeric biliary endoprostheses. Biomaterials. 2001;22(23): 3113-3119.

35. Donelli G, Guaglianone E, Di Rosa R, et al. Plastic biliary stent occlusion: factors involved and possible preventive approaches. Clin Med Res. 2007;5(1):53-60.

36. Seitz U, Block A, Schaefer AC, et al. Biliary stent clogging solved by nanotechnology? In vitro study of inorganic-organic sol-gel coatings for Teflon stents. Gastroenterology. 2007;133(1):65-71. 


\section{Supplementary material}

Table SI General data of beagle canine model

\begin{tabular}{|c|c|c|c|c|c|}
\hline Earmark & Sex & Birth date & Father & Mother & Weight (kg) \\
\hline A07I & $\mathrm{F}$ & $20 \mid 4-I-20$ & A83I & A0619 & 11 \\
\hline A072 & $\mathrm{F}$ & $20|4-|-20$ & A83I & A0619 & 10.5 \\
\hline A073 & $M$ & $20|4-|-20$ & A83I & A0619 & 10 \\
\hline A074 & $M$ & $20 \mid 4-I-20$ & A83I & A0619 & 10 \\
\hline A075 & $M$ & $20|4-|-20$ & A83I & A0619 & 10.5 \\
\hline A076 & $M$ & $2014-\mid-22$ & A677 & $\mathrm{A} 4 \mathrm{I} 2 \mathrm{I}$ & II \\
\hline A077 & $M$ & $2014-1-22$ & A677 & $A 4 \mid 2 I$ & 11 \\
\hline A078 & $\mathrm{F}$ & $2014-\mid-22$ & $\mathrm{~A} 677$ & $A 4 \mid 2 I$ & 12 \\
\hline A079 & $\mathrm{F}$ & $2014-1-22$ & A677 & $A 4 \mid 2 I$ & 12.5 \\
\hline A080 & $\mathrm{F}$ & $2014-1-22$ & A677 & $\mathrm{A} 4 \mid 2 \mathrm{I}$ & 11.5 \\
\hline A08I & $\mathrm{F}$ & $20|4-|-25$ & A725 & A4053 & 10.5 \\
\hline A082 & $M$ & $2014-\mid-25$ & A725 & A4053 & 12 \\
\hline
\end{tabular}

Abbreviations: $M$, male; $F$, female.

\section{Publish your work in this journal}

The International Journal of Nanomedicine is an international, peerreviewed journal focusing on the application of nanotechnology in diagnostics, therapeutics, and drug delivery systems throughou the biomedical field. This journal is indexed on PubMed Central, MedLine, CAS, SciSearch ${ }^{\circledR}$, Current Contents ${ }^{\circledR} /$ Clinical Medicine,

\section{Dovepress}

Journal Citation Reports/Science Edition, EMBase, Scopus and the Elsevier Bibliographic databases. The manuscript management system is completely online and includes a very quick and fair peer-review system, which is all easy to use. Visit http://www.dovepress.com/ testimonials.php to read real quotes from published authors.

\footnotetext{
Submit your manuscript here: http://www.dovepress.com/international-journal-of-nanomedicine-journal
} 